\title{
EFFECT OF HUMAN RHINOVIRUS INFECTION ON AIRWAY EPITHELIUM TIGHT JUNCTION PROTEIN DISASSEMBLY AND TRANSEPITHELIAL PERMEABILITY
}

Kevin Looi ${ }^{1}$, Niamh M. Troy ${ }^{2}$, Luke W. Garratt ${ }^{1,2}$, Thomas Iosifidis ${ }^{1,3}$, Anthony Bosco ${ }^{2}$, Alysia G. Buckley $^{4}$, Kak-Ming Ling ${ }^{2}$, Kelly M Martinovich ${ }^{2}$, Elizabeth Kicic-Starcevich ${ }^{2}$, Nicole C. Shaw ${ }^{2}$, Erika N. Sutanto ${ }^{2,5}$, Graeme R. Zosky ${ }^{6}$, Paul J. Rigby ${ }^{4}$, Alexander N. Larcombe ${ }^{2}$, Darryl A. Knight $^{7,8,9}$, Anthony Kicic ${ }^{1,2,3,5^{*}}$ \& Stephen M. Stick ${ }^{1,2,3,5^{*}}$

1: School of Paediatrics and Child Health, The University of Western Australia, Nedlands, 6009, Western Australia, Australia.

2: Telethon Kids Institute, Centre for Health Research, The University of Western Australia, Crawley, 6009, Western Australia, Australia.

3: Centre for Cell Therapy and Regenerative Medicine, School of Medicine and Pharmacology, The University of Western Australia, Nedlands, 6009, Western Australia, Australia.

4: Centre of Microscopy, Characterization and Analysis, The University of Western Australia, Crawley, 6009, Western Australia, Australia.

5: Department of Respiratory Medicine, Princess Margaret Hospital for Children, Perth, 6001, Western Australia, Australia.

6: School of Medicine, Faculty of Health, University of Tasmania, Hobart, 7000, Tasmania, Australia 7: School of Biomedical Sciences and Pharmacy, University of Newcastle, Callaghan, New South Wales, Australia.

8: Priority Research Centre for Asthma and Respiratory Disease, Hunter Medical Research Institute, Newcastle, New South Wales, Australia

9: Department of Anesthesiology, Pharmacology and Therapeutics, University of British Columbia, Vancouver, Canada. 
*: Authors contributed equally to this work

To whom correspondence should be addressed: A/Prof Anthony Kicic, Telethon Kids Institute, 100 Roberts Road, Subiaco, Perth, WA 6008. Phone: (618) 9340 8140, Fax: (618) 9340 7429. Email: anthony.kicic@telethonkids.org.au 


\section{ABSTRACT}

Rationale: No studies have assessed the effects of HRV infection on epithelial tight junctions (TJ) and resultant barrier function.

Aim: To correlate viral infection with TJ disassembly, epithelial barrier integrity and function.

Methods: Human airway epithelial cells were infected with HRV-1B at various Tissue Culture Infectivity Doses (TCID 50 ) over 72 hours. HRV replication was assessed by qPCR while cell viability and apoptosis were assessed by proliferation and apoptotic assays respectively. Protein expression of claudin-1, occludin and zonula occludens-1 (ZO-1) was assessed using In-Cell ${ }^{\mathrm{TM}}$ Western assays. Transepithelial permeability assays were performed to assess effects on barrier functionality. $\mathrm{RT}^{2}$ Profiler focused qPCR arrays and pathway analysis evaluating associations between human TJ and anti-viral response were performed to identify potential interactions and pathways between genes of interests.

Results: HRV-1B infection affected viability that was both time and TCID 50 -dependant. Significant increase in apoptosis and viral replication post infection correlated with viral titre. Viral infection Significant decrease in claudin-1 protein expression at the lower TCID $_{50}$ while significant decrease in all $3 \mathrm{TJ}$ protein expression occurred at higher $\mathrm{TCID}_{50}$. Decrease in protein expression was concomitant with significant increase in epithelial permeability of FITC-dextran 4 and $20 \mathrm{kDa}$. Analysis of focused qPCR arrays demonstrated significant decrease in ZO-1 gene expression. Furthermore, network analysis between human TJ and anti-viral response genes revealed possible interactions and regulation of TJ genes via IL-15 in response to HRV-1B infection.

Conclusion: HRV-1B infection directly alters human airway epithelial TJ expression leading to increased epithelial permeability potentially via an anti-viral response of IL-15.

Keywords: Airway epithelial cells, tight junctions, human rhinovirus, epithelial barrier 


\section{INTRODUCTION}

A pseudostratified mucosal barrier consisting of a multitude of cell types functions as the initial protective interface between the internal milieu of the lung and the external environment of microorganisms, aeroallergens and noxious gases within the human respiratory tract. A range of junctional complexes including tight junctions, adherens junctions, GAP junctions, desmosomes and connexins maintain this protective barrier. Tight junctions (TJ) are typically located at the apical borders of adjacent epithelial cells where they serve to regulate the movement of ions and solutes as well as to prevent unwanted migration of pathogens and their products to the sub-epithelial space (1). A compromised epithelial barrier function, including disruption in the TJ protein, zonula occludens protein-1 (ZO-1) has been shown to increase the paracellular traffic of pathogenic molecules into the lung interstitium (2). Furthermore, a compromised barrier integrity has also been correlated to the release of pro-inflammatory cytokines including interlukin-8 (CXCL8), eotaxin (CCL11), regulated on activation, normal T-cell expressed and secreted (RANTES/CCL5), interferon-inducible protein10 (CXCL10) and macrophage inflammatory protein $1 \alpha$ (CCL3) (3).

Airway barrier integrity may become compromised after exposure to injurious stimuli including airborne pollutants, aeroallergens, bacteria and respiratory viruses. Respiratory viruses such as human rhinovirus (HRV) are common insults to the airway epithelium. Despite evidence suggesting that a significant reduction in TJ protein expression and a disassembly of the apical junction proteins is associated with an attenuated barrier function $(2,4,5)$, the pathways involved in the regulation of airway epithelial TJ proteins following HRV infection and the effects on barrier function are not well understood. Furthermore, altered expression of a single TJ is commonly reported within the literature and most studies rarely assess the interactions and expression of multiple TJs following airway insults. Hence, translation of such research findings often remains a challenge due to the multitude of junctional proteins and the potential compensatory effects in response to airway insults. In addition, there is evidence demonstrating the direct expression relationships between different TJs and 
epithelial integrity $(6,7)$. Three of note include; claudin-1, which is ubiquitously expressed within the human airways (8); occludin and ZO-1, both of which have been demonstrated to being integral in the maintenance of epithelial integrity $(9,10)$.

Hence, this investigation was conducted to investigate any direct correlation between HRV infection, altered TJ expression and transepithelial permeability by utilizing hTERT modified human airway epithelial cells (AEC). Specifically, this study tested the hypothesis that TJ protein expression of claudin-1, occludin and ZO-1 would be significantly reduced following HRV infection resulting in increased epithelial permeability. We performed all experiments on undifferentiated cultures grown in monolayer culture, since it has previously been shown that differentiated cultures are more resistant to HRV infection (11) and that basal cells are the primary target of HRV (12). This allowed us to clearly identify the dissociative effects of HRV infection on multiple epithelial junctional proteins as well as correlating these effects with attenuation of barrier functionality.

Our results show a time and $\mathrm{TCID}_{50}$-dependant effect of viral infection on cell viability, while infection resulted in significant increases in both cellular apoptosis and viral replication that correlated to viral titres. In addition, protein expression for claudin-1, occludin and ZO-1 was significantly reduced following $\mathrm{HRV}-1 \mathrm{~B}$ infection. Concomitant with this decrease, epithelial permeability was significantly increased following infection. Furthermore, expression of 58 genes encoding epithelial tight junctional proteins such as claudin-1, occludin and ZO-1 were downregulated following HRV infection. Gene network reconstruction identified a signalling pathway in which gene expression of TJ were potentially mediated via an anti-viral response of IL-15. Collectively, these observations show that infection with HRV-1B in healthy AEC directly alters TJ protein expression, resulting in a disruption of epithelial barrier integrity through junctional disassembly, subsequently leading to an attenuated barrier function. 


\section{MATERIALS AND METHODS}

\section{Patient and sample collection}

Airway epithelial cells were obtained from 3 children with no history of asthma (Table 1) undergoing elective surgery for non-respiratory-related conditions. Children with an existing bacterial or viral chest infection were excluded from the study. Primary AECs were isolated and established as previously described (13-16). The study was approved by both Princess Margaret Hospital for Children and St John of God Hospital's Human Ethics Committee.

\section{Cells}

Human airway epithelial cells, modified by hTERT to express exogenous telomerase, (NuLi-1) were obtained from the American Type Culture Collection (ATCC). Cells were cultured in bronchial epithelial basal medium (BEBM) supplemented with SingleQuot additives (Lonza) and maintained at $37^{\circ} \mathrm{C}$ in an atmosphere of $5 \% \mathrm{CO}_{2} / 95 \%$ air. For expansion, cells were washed with HEPES buffered saline solution (HBSS) (Lonza) and detached from the culture vessels by incubating with Trypsin-Ethylenediaminetetraacetic acid (T-EDTA) (Lonza) solution for 4 minutes (min) at $37^{\circ} \mathrm{C}$. Culture vessels were then washed with Trypsin Neutralizing Solution (Lonza) and culture media and the resulting cell suspension collected and centrifuged at $500 \mathrm{~g}$ for $7 \mathrm{~min}$ at $4^{\circ} \mathrm{C}$. The supernatant was then aspirated and the cell pellet re-suspended in the growth medium. A total cell count and viability stain was also performed. Cells were plated at $2 \times 10^{4}$ cells $/ \mathrm{cm}^{2}$ into new tissue culture vessels and maintained as described above.

\section{Rhinovirus and titrations}

Human rhinovirus minor serotype 1B (HRV-1B) was provided by Professor Peter Wark (Hunter Medical Research Institute, Newcastle, NSW, Australia). To determine viral titers, MRC-5 cells were grown in 96-well flat bottom tissue culture plates and infected with 10-fold serial dilutions of virus 
in 8 replicates. Culture plates were incubated for 5 days and the wells assessed daily for cytopathic effect (CPE) by microscopic evaluation. The tissue culture infectivity dose (TCID 50 ) of the virus was calculated based upon the 5 day CPE utilizing the Reed Muench method. All HRV-mediated responses were confirmed to be specific to active virus, since UV-inactivation of viral stocks for 120 min resulted in a lack of replication in MRC-5 cells (data not shown).

\section{Infection of cell cultures}

Cells were grown on tissue culture plates or inserts, were infected with HRV-1B or an equivalent volume of UV-inactivated sham control and incubated over 72 hours depending on the assay. Briefly, growth media was replaced with fresh basal media and subsequently infected with HRV-1B at a 50\% Tissue Culture Infectivity Dose (TCID 50 ) of $2.5,10,20,40$ or 80 x $10^{4} \mathrm{TCID}_{50} / \mathrm{ml}$. After each incubation period, media was collected and stored at $-80^{\circ} \mathrm{C}$ and cells utilized in various downstream functional assays. Primary AECs were similarly grown on tissue culture plates or inserts and infected with HRV-1B at a 50\% Tissue Culture Infectivity Dose (TCID 50 ) of 10 x $10^{4} \mathrm{TCID}_{50} / \mathrm{ml}$ for 24 hours. We have previously demonstrated a dose and time dependent effect of HRV-1B on cell viability above this dose on primary AECs (17). At the end of the incubation period, media was similarly collected, stored at $-80^{\circ} \mathrm{C}$ and cells used for membrane tight junction protein and epithelial permeability assessment.

\section{Cell viability assay}

To determine the effects of HRV-1B on viability, cells were seeded into 96-well plates and grown to $80 \%$ confluence. HRV-1B was added to the wells between $2.5 \times 10^{4}$ and $80 \times 10^{4} \mathrm{TCID}_{50} / \mathrm{ml}$ for 24 , 48 and 72 h. Following exposure, cell viability was assessed using a 3-[4,5-dimethylthiazol-2yl]-5[3-carboxymethoxyphenyl]-2-[4-sulfophenyl]-2H-tetrazolium inner salt (MTS) assay (Promega) (18). 


\section{Single-stranded DNA (ssDNA) apoptosis assay}

To determine the percentage of cells that underwent apoptosis during HRV exposure, a ssDNA apoptosis ELISA kit was utilized as previously described (19). This procedure is based upon the selective denaturation of DNA in apoptotic cells by formamide and the detection of denatured DNA with a specific monoclonal antibody for ssDNA. Briefly, cells were plated onto 96-well microplates pre-coated with fibronectin $(10 \mathrm{mM})$ at a seeding density of $6 \times 10^{4}$ cells $/ \mathrm{cm}^{2}$ and incubated at $37^{\circ} \mathrm{C}$ in an atmosphere of $5 \% \mathrm{CO}_{2} / 95 \%$ air in $\mathrm{BEBM}$ containing growth supplements as described earlier. Cells were then infected with HRV-1B at three viral concentrations: $2.5 \times 10^{4}$ TCID $50 / \mathrm{ml}, 10 \times 10^{4}$ $\mathrm{TCID}_{50} / \mathrm{ml}$ and $80 \times 10^{4} \mathrm{TCID}_{50} / \mathrm{ml}$ for 24 hours. Cells were fixed and the assay as performed in accordance with the manufacturer's instruction (Chemicon).

\section{Quantification of HRV viral copy number}

Viral copy number was determined quantitatively via two-step RT-PCR reactions using a HRV-1B advanced kit (PrimerDesign ${ }^{\mathrm{TM}}$ Ltd) in combination with MultiScribe ${ }^{\mathrm{TM}}$ Reverse Transcriptase and Taqman ${ }^{\circledR}$ Universal Master Mix (Thermo Fisher Scientific) as previously described (19).

\section{In-Cell Western ${ }^{\mathrm{TM}}$ Assay}

Cells were plated at $1.2 \times 10^{5}$ cells $/ \mathrm{cm}^{2}$ onto 96 -well plates pre-coated with fibronectin $(10 \mathrm{mM})$ and maintained as described earlier. When confluent, growth media was aspirated and cell monolayer immediately fixed using $150 \mu \mathrm{l}$ of $3.7 \%$ formaldehyde for $20 \mathrm{~min}$ at room temperature (RT). Permeabilization of the cells was achieved by washing five times with $1 \mathrm{X}$ phosphate buffered saline (PBS) containing $0.1 \%$ Triton-X-100 for 5 min per wash with gentle shaking. However, this was only performed on half of the experimental setup to determine total protein expression. Concurrently, non- 
permeabilized cells of the experimental setup was incubated with only $1 \mathrm{X}$ PBS. This allowed for the determination of membrane protein expression. Blocking was performed for $90 \mathrm{~min}$ at RT using 150 $\mu 1$ of Odyssey Blocking Buffer and subsequently, cells were then incubated with primary antibodies specific to zonal occludin-1 (1:200, Invitrogen), claudin-1 (1:200, Invitrogen) and occludin (1:200, Invitrogen) for 24 hours at $4^{\circ} \mathrm{C}$. After this period, cells were washed five times at RT in $1 \mathrm{X}$ PBS containing $0.1 \%$ Tween-20 for 5 min per wash and incubated with near-infrared (NIR) fluorescent dye conjugated-secondary antibody (1:800, Licor Biosciences) containing cellular nuclear stains DRAQ5 (1:10000, Biostatus Limited) and Sapphire700 (1:1000, Licor Biosciences) for 1 hour at RT with gentle shaking within a dark room. Cells were then washed for an additional five times in $1 \mathrm{X}$ PBS containing $0.1 \%$ Tween-20. Specific antibody staining for protein expression was then immediately visualized using a two NIR laser imaging system for the excitation of NIR fluorescent dye conjugated-secondary antibodies bound onto the target proteins. The obtained fluorescence is then converted to an integrated intensity values through the accompanying image analysis software which can then be normalized to cell numbers stained by the cellular nuclear stains (Licor Biosciences).

\section{Transepithelial permeability}

Cells were plated at a seeding density of $1.2 \times 10^{5}$ cells $/ \mathrm{cm}^{2}$ onto rat-tail collagen coated culture inserts (BD Biosciences) and maintained as described earlier. When confluent, transepithelial permeability was assessed using a transepithelial permeability assay with fluorescein isothiocynate labeled dextran (FITC-dextran) to determine apparent permeability of HRV-1B infected and noninfected control inserts. Growth media within the apical and basolateral compartments was replaced with HEPES buffered Hank's balanced salt solution (HBSS-HEPES). FITC-dextran of molecular weight $4 \mathrm{kDa}$ or $20 \mathrm{kDa}(2 \mathrm{mg} / \mathrm{ml})$ was added to the apical chamber and $50 \mu \mathrm{l}$ of this solution immediately sampled. A $500 \mu \mathrm{l}$ volume of solution was removed from the basolateral compartment 
at hourly intervals for a period of 6 hours. The volume of the basolateral compartment was maintained by addition of fresh buffered HBSS-HEPES. All experiments were performed at $37^{\circ} \mathrm{C}$ and on a calibrated orbital shaker at $300 \mathrm{rpm}$ to minimize the unstirred water layer. Fluorescence of FITCdextran was detected using an Enspire multilabel fluorescence counter (PerkinElmer) at an excitation wavelength of $492 \mathrm{~nm}$ and emission wavelength of $520 \mathrm{~nm}$. The apparent permeability of the epithelial monolayer to FITC-dextran from the apical to basolateral compartment $\left(\mathrm{P}_{\mathrm{app}}\right)$ was then calculated as previously described (20).

\section{Human tight junction and anti-viral response $\mathbf{R T}^{2}$ Profiler focused quantitative-polymerase chain reaction (qPCR) analysis}

Cells were infected with a viral titer of $10 \times 10^{4} \mathrm{TCID}_{50} / \mathrm{ml}$ for $9 \mathrm{~h}$ (to encompass the reproductive cycle of the virus) and subsequently collected for RNA. Transcript levels of specific genes associated with human TJ and the anti-viral response were analysed as part of two separate $\mathrm{RT}^{2}$ Profiler focused qPCRs, each consisting of 84 key genes encoding proteins forming the epithelial barrier and the antiviral responses respectively (QIAGEN). Total RNA was extracted using a RNeasy mini kit (QIAGEN) 9 hours post HRV-1B infection. After generating cDNA from $1 \mu \mathrm{g}$ total RNA using RT ${ }^{2}$ PCR First Strand Kit (QIAGEN), quantitative PCR was performed on an ABI Prism ${ }^{\circledR} 7300$ (Thermo Fisher Scientific) in accordance with the manufacturer's protocol.

To gain insight into the relationship between human TJ genes and genes involved in the anti-viral response, the wiring network of these genes was reconstructed in the context of known biological response and regulatory networks using Ingenuity ${ }^{\circledR}$ Pathways Analysis (IPA $\left.{ }^{\circledR}\right)$. 


\section{Statistics}

Before statistical evaluation, all results were tested for population normality and homogeneity of variance. Experiments were performed in at least triplicates and all data was considered nonparametric. For these data, analysis was performed using Kruskal-Wallis test with Dunn's multiple comparison post-hoc test. Data was presented as whisker box plots (median, Min - Max) and all $p$ values less than 0.05 were considered to be significant. 


\section{RESULTS}

\section{Effect of human rhinovirus infection on airway epithelial viability, apoptosis and viral replication}

Although HRV has been reported to have a cytotoxic effect on primary airway epithelial cells (21), the effects on epithelial tight junction and barrier function together, remains largely unanswered. Hence cytotoxicity assays were performed initially to determine the effects of HRV-1B infection on cell viability. Figure 1 shows that infection with HRV-1B reduced viability in a dose and time dependent manner. Specifically, infection of AEC with HRV-1B between $2.5 \times 10^{4}$ and $10 \times 10^{4}$ $\mathrm{TCID}_{50} / \mathrm{ml}$ had a minor effect on viability $(93.2$ - 100\%) (Figure 1A). However, when infected for 24 hours with the viral titer of $20-80 \times 10^{4} \mathrm{TCID}_{50} / \mathrm{ml}$, a significant loss of viability was observed (Figure $1 \mathrm{~A} ; \mathrm{p}<0.05)$. Incubation for $48-72$ hours produced a significant loss in AEC viability at all TCID50.

Apoptotic responses in virally infected cells are key protective mechanisms to prevent and minimize viral replication and release. Hence, we assessed apoptosis 24 hours following infection with HRV1B. A significant dose-dependent apoptotic response was observed post infection with all viral titers, ranging from 55 - $88 \%$ over control levels (Figure 1B; $\mathrm{p}<0.05$ ). Furthermore, increasing amounts of HRV RNA was detected, concomitant with the increase in viral titer used in the infection. (Figure $1 \mathrm{C} ; \mathrm{p}<0.05)$

\section{Effect of human rhinovirus infection on membrane tight junction disassembly}

$\mathrm{In}^{-C e l l}{ }^{\mathrm{TM}}$ Western assays were utilized to corroborate membrane protein disassembly of claudin-1, occludin and ZO-1. There was high endogenous occludin expression $(0.038 \mathrm{AU} \pm 0.007)$ within the airway epithelial cells, while, endogenous claudin-1 and ZO-1, which demonstrated similar levels of expression were significantly lower $(0.015 \mathrm{AU} \pm 0.002$ and $0.016 \mathrm{AU} \pm 0.002$ respectively) (Figure $2 \mathrm{~A}$ and $\mathrm{C}-$ non-infected; $\mathrm{p}<0.05)$. Following HRV-1B infection at a low viral titer to simulate chronic infectivity $\left(2.5 \times 10^{4} \mathrm{TCID}_{50} / \mathrm{ml}\right)$, a significant decrease in claudin-1 expression $(0.007 \mathrm{AU} \pm 0.0002$; 
$\mathrm{p}<0.05)$ was observed and although both occludin and ZO- 1 expression was reduced $(0.02 \mathrm{AU} \pm 0.001$ and $0.012 \mathrm{AU} \pm 0.0004$ respectively), this did not reach statistical significance. When infected at a higher viral titer, similar to an acute infection $\left(20 \times 10^{4} \mathrm{TCID}_{50} / \mathrm{ml}\right)$, significant decreases in all membrane protein expressions of claudin-1 $(0.007 \mathrm{AU} \pm 0.0001 ; \mathrm{p}<0.05)$, occludin $(0.016 \mathrm{AU} \pm 0.002$; $\mathrm{p}<0.05)$ and $\mathrm{ZO}-1(0.007 \mathrm{AU} \pm 0.00009 ; \mathrm{p}<0.05)$ were observed compared to controls (Figure $2 \mathrm{~A}$ and $\mathrm{C} ; \mathrm{p}<0.05)$.

When membrane protein disassembly was assessed in primary AECs, similar high endogenous occludin expression was demonstrated followed by claudin-1 and ZO-1 respectively (Figure $2 \mathrm{~B}$ and D). When infected with HRV-1B at a viral titre of $10 \times 10^{4} \mathrm{TCID}_{50} / \mathrm{ml}$, significant decrease in all $3 \mathrm{TJ}$ membrane protein expression was observed compared to controls (Figure $2 B$ and $D ; p<0.05$ ).

\section{Effect of human rhinovirus infection on transepithelial permeability}

Epithelial paracellular permeability is a key functional indicator of cellular junctional integrity. Hence, to correlate HRV-1B induced disassembly of membrane TJ with barrier function, a transepithelial permeability assay was performed. Following infection with $2.5 \times 10^{4} \mathrm{TCID}_{50} / \mathrm{m}$ of HRV-1B, a significant increase in permeability to FITC-dextran of 4kDa $\left(292.6 \pm 2.4 \times 10^{-4} \mathrm{~cm} / \mathrm{sec}\right.$; $\mathrm{p}<0.05)$ and $20 \mathrm{kDa}\left(249.8 \pm 10.33 \times 10^{-4} \mathrm{~cm} / \mathrm{sec} ; \mathrm{p}<0.05\right)$ was observed compared to controls $(221.9$ $\pm 8.5 \times 10^{-4} \mathrm{~cm} / \mathrm{sec}$ and $115 \pm 4.5 \times 10^{-4} \mathrm{~cm} / \mathrm{sec}$ respectively) (Figure 2E). Interestingly, when cells were infected with a higher viral titer $\left(20 \times 10^{4} \mathrm{TCID}_{50} / \mathrm{ml}\right)$, significant increases in transepithelial permeability of FITC-dextran $4 \mathrm{kDa}\left(357.9 \pm 12.2 \times 10^{-4} \mathrm{~cm} / \mathrm{sec} ; \mathrm{p}<0.05\right)$ and $20 \mathrm{kDa}(302.2 \pm 7.2 \mathrm{x}$ $\left.10^{-4} \mathrm{~cm} / \mathrm{sec} ; \mathrm{p}<0.05\right)$ was observed when compared to controls $\left(221.9 \pm 8.5 \times 10^{-4} \mathrm{~cm} / \mathrm{sec}\right.$ and $115 \pm$ $4.5 \times 10^{-4} \mathrm{~cm} / \mathrm{sec}$ respectively) (Figure $2 \mathrm{E}$ ).

Moreover, elevated permeability to FITC-dextran $4 \mathrm{kDa}$ was observed to be significantly higher $\left(292.6 \pm 2.4 \times 10^{-4} \mathrm{~cm} / \mathrm{sec}\right.$ and $\left.357.9 \pm 12.2 \times 10^{-4} \mathrm{~cm} / \mathrm{sec}\right)$ when compared to $20 \mathrm{kDa}(249.8 \pm 10.33 \mathrm{x}$ 
$10^{-4} \mathrm{~cm} / \mathrm{sec}$ and $302.2 \pm 7.2 \times 10^{-4} \mathrm{~cm} / \mathrm{sec}$ ) post-infection with both viral titres respectively (Figure $2 \mathrm{E} ; \mathrm{p}<0.05)$.

When transepithelial permeability was assessed in primary AECs, similar significant increase in epithelial permeability to FITC-dextran 4kDA was observed post-infection when compared to controls (Figure 2F; $\mathrm{p}<0.05$ ). In addition, increased permeability to FITC-dextran 4kDa was similarly observed to be significantly higher when compared to $20 \mathrm{kDa}$, at non-infected and post-infection levels (Figure 2F; $\mathrm{p}<0.05$ ).

\section{Effects of HRV-1B infection on mRNA expression of tight junction and anti-viral responses}

In order to directly correlate HRV infection with altered expression in tight junction associated proteins, a $\mathrm{RT}^{2}$ Profiler focused qPCR was performed. Following infection with HRV-1B for 9 hours, 58 genes encoding for epithelial tight junctional proteins were down-regulated with the most downregulated being CLDN8 (14.2-fold). Conversely, 26 genes were up-regulated following HRV-1B infection, with the most up-regulated being Crb3 (1.9-fold). From our data, significant downregulation was observed for CLDN8 (14.2-fold), PTEN (3.5-fold), CLDN12 (2.3-fold), ASH1L (1.9fold), and TJP1 (ZO-1) (1.3-fold) (Table 2; p<0.05). Our data demonstrated down-regulation of mRNA for claudin-1 (1.1-fold), occludin (1.2-fold) and ZO-1 (1.3-fold) following HRV-1B infection. However, infection did not have a significant effect on the transcript expression of both claudin-1 and occludin but was only observed for ZO-1 (Table 2 - TJP1; $<<0.05$ ). Down-regulation of ZO-1 transcripts levels following HRV-1B infection was concomitant with a significant decrease in protein expression levels (Figure 2C $-\mathrm{ZO}-1 ; \mathrm{p}<0.05$ ). Beyond the genes of interest, we assessed a number of the more differentially expressed genes including PTEN and corroborated that down-regulated transcript levels were paralleled with significant decreases in protein expression levels following HRV-1B infection (data not shown). 
Infection with HRV-1B resulted in the down-regulation of 41 genes encoding for anti-viral responses with the most significant being CXCL9 (2.9-fold) (Table 3; p<0.05). Conversely, 43 genes were shown to be up-regulated post infection, with the most significant being IFNA2 (6.1-fold) (Table 3; $\mathrm{p}<0.05$ ). Of these, 36 genes were determined to be significantly up-regulated (Table $3 ; \mathrm{p}<0.05$ ).

\section{Network interactions of tight junction genes and anti-viral responses}

Utilizing the molecular interaction data from the Ingenuity Systems Knowledge base to construct a network interaction diagram, our analysis revealed that tight junction protein 1 (TJP1) or ZO-1 was the most highly interactive gene in the human TJ network, exhibiting 26 functional interactions with other TJ genes while occludin and claudin exhibited 12 and 9 functional interactions with other TJ genes respectively (Figure 3A). Additional construction of network interaction diagrams between tight junction and anti-viral response genes illustrated multiple, complex interactions and identified IL15 as a hub gene with high connectivity within the anti-viral network (33 connections). Furthermore, IL15 was connected to 7 genes within the TJ network including both TJPI and OCLN, revealing a potential regulatory mechanism of $I L 15$ on the TJ network. (Figure 3B).

\section{DISCUSSION}

The mechanisms that explain how HRV infection impact on the expression and regulation of tight junction genes and subsequent disassembly of TJ proteins resulting in impairment of epithelial barrier functions are poorly understood. Previous studies have used cell lines or primary AECs for understanding the effects of viral infection on membrane TJ dissociation alone or disassembly in membrane TJ proteins leading to an observed increase in epithelial permeability $(2,4,22)$. However, no single study has yet incorporated both and at present, this is the first in which the effects of HRV on multiple TJ gene expression, disassembly of membrane TJ proteins and subsequent impairment 
on transepithelial permeability have been examined. Findings from this study also demonstrated the dynamic relationships between various TJs as well as provide evidence for the need to include multiple junctional proteins rather than a single protein for the assessment of epithelial barrier integrity.

Airway epithelial cells are of vital importance during viral infections as they serve as the host cell for viral replications as well as initiating the innate and adaptive immune responses. Previous studies have demonstrated that primary AECs are susceptible to viral infections and that HRV is able to successfully replicate resulting in a cytotoxic effect $(19,23-25)$. However, limited access to primary AECs as well as variability between different donor epithelia often restricts and confounds the ability to accurately interpret the generated data. Hence, utilizing modified human AECs, this study, in addition to providing proof of principle of the direct associations between HRV infection with changes in multiple TJ genes, proteins expression and resulting functional effect manifested as alterations in transepithelial permeability also demonstrates potential pathways for the regulation of epithelial junctional proteins via anti-viral responses.

Our data confirmed previously reported associations between viral titers of HRV-1B with cell viability, apoptosis and viral replication $(19,21)$. This demonstrates the suitability of the modified human AEC as an intermediary culture model bridging immortalized cell lines and primary human derived AEC for the assessment of HRV-1B induced effects on airway epithelial mechanics such as barrier integrity via junctional protein complex expression.

Tight junction complexes which are the most apical of the junctional complex family not only serve to provide intercellular adhesion but also form a continuous permeability barrier which regulates the trafficking of molecules across the epithelial layer (26). Numerous junctional complexes interact to provide structural support for the regulation and integrity of airway epithelium. Recent evidence has 
demonstrated the coordinated involvement of multiple domains of the TJ protein, $\mathrm{ZO}-1$ in the assembly of a normal and functioning epithelial barrier (7). Moreover, studies have also demonstrated the integral role of ZO-1 as a scaffolding protein necessary for the localization of both claudin-1 and occludin $(6,7)$ for the formation of cell to cell contacts. Hence, perturbations in these integral TJ complexes would likely result in increased epithelial permeability, facilitating the traffic of aeroallergens or pathogens as well as increased exposure of basolateral receptors to the inhaled air.

We demonstrated significantly reduced protein expression of claudin-1, occludin and ZO-1 following infection with HRV-1B indicating the disassembly of membrane claudin-1, occludin and ZO-1 junctions post infection. In addition, disassembly of these TJ protein complexes results in increased transepithelial permeability of macromolecules, in particular, small sized macromolecules. Importantly, these observations were subsequently corroborated in a series of experiments using primary AECs, confirming our findings. Collectively, our observations demonstrate the effects of HRV-1B infection on the dissociation of membrane claudin-1, occludin and ZO-1, which corresponds with an elevated epithelial permeability. Observations from this study suggest that an altered epithelial permeability towards different sized macromolecules could possibly result in increased exposure of basolateral receptors thereby facilitating elevated viral entry and eventual dissemination throughout the respiratory system. Increased transepithelial permeability following viral infection can result in transmigration of bacteria into the sub-epithelial space, an observation reported by Sajjan and co-workers (2008). This would have serious implications for individuals with asthma (27) as the consequence of such an increased epithelial permeability to respiratory viruses or bacteria could enhance airway inflammation. This could lead to recurrent disease exacerbations through generation of a variety of pro-inflammatory cytokines including IL-1 $\beta$, IL-6, GM-CSF and IL-11 (28-30) as well as chemokines such as CXCL8, CXCL10 and CCL5 (23, 31-33) ultimately resulting in chronic airway inflammation and eventually, structural remodelling (34-36). 
We performed $\mathrm{RT}^{2}$ Profiler focused qPCRs of HRV infected AECs and using the data obtained, constructed network interaction pathways to elucidate the interactions between junctional proteins and anti-viral responses and also to propose potential regulatory mechanisms of TJ by anti-viral responses. Our data showed, the down-regulation of 58 genes and up-regulation of 26 genes encoding for epithelial barrier junction proteins; and the down-regulation of 29 genes and up-regulation of 36 genes encoding for anti-viral responses. Expression of the ubiquitous claudin-1 (CLDN1), was downregulated. In a study by Coyne and colleagues, the authors characterized claudin expression in normal human airways and determined that claudin 1 and 3 interacted to contribute towards decreased epithelial permeability while expression of claudin 5 resulted in a leakier epithelium (8). Our data demonstrates that following HRV-1B infection, there is a decrease in the expression of the associated TJ genes of the studied TJ proteins, namely claudin-1, occludin and ZO-1, although significance was only observed for $Z O-1$ (TJP1). In a study by Yeo and colleague (37), they demonstrated the effects of HRV-1B on modulating TJ gene expression and illustrated the effects on claudin-1, occludin and ZO-1 gene expression. However, as demonstrated in our focused qPCR data, infection with HRV-1B did not only affect the TJ genes of interest, but other genes responsible for epithelial barrier integrity.

Our unique observation that gene networks associated with HRV-induced disassembly of tight junctions and anti-viral responses are linked, has implications for diseases such as asthma and cystic fibrosis in which impaired innate immune responses have been observed (38-40). Innate immune responses to viral infections are triggered when the viral proteins and nucleic acids are detected by pattern recognition receptors, which in turn activate the intracellular signalling cascades, converging on the IRF and NF- $\kappa \mathrm{B}$ families of transcription factors (41). These transcription factors then translocate to the nucleus where the activation of anti-viral and inflammatory processes is initiated. Our findings identified an up-regulation of the transcription factor interferon regulatory factor-3 (IRF3) with HRV-1B infection. IRF3 normally resides within the cytoplasm in an inactive form but undergoes a conformational change through phosphorylation and dimerization, leading to nuclear 
translocation upon viral infection. Nuclear localization of IRF3 subsequently forms a complex with co-activators CBP and / or p300, resulting in the binding to target DNA sequence in type I interferon, cytokine and chemokine genes and subsequent activation following viral infection (42-44). Our data identifies a potential causal regulatory mechanism, where an up-regulation of IRF3 would lead to increased expression of type I interferons (IFN) such as IFN- $\alpha$ and $-\beta$ as well as cytokines such as IL-15, which in turn result in the down-regulation of TJ expression. IRF7, which has also been implicated in the regulation of antiviral responses, was similarly identified in our data but was downregulated upon virus infection. This was in contrast to the data reported by Bosco and colleagues, where they identified an up-regulation of IRF7 following virus infection (45). This dissimilarity could be attributed to several factors differing between the experimental designs in these studies including, (1) HRV strains utilized; (2) viral titers used for infection and (3) length of infection before collection of total RNA for gene expression analysis. Interestingly, low or diminished IRF7 expression has been previously associated with an elevated expression of genes involved in the response to oxidative stress (46-49). These observations, together with a study conducted by Comstock and colleagues (22) where they demonstrated impairment of epithelial barrier functions due to reactive oxygen species, further implicates the probable indirect associations of $I R F 7$ in regulating barrier integrity. Follow-up studies are not underway to elucidate the relationship of the IRF-family of transcription factors in modulating antiviral responses as well as airway epithelial barrier integrity and function.

This study, having established the associations between TJ protein expression and barrier functionality in response to HRV infection within healthy AECs as well as the possible mechanisms behind the regulation of epithelial junctional proteins, provides the opportunity to further investigate the gene and protein expression levels in AECs of diseased airways. However, we acknowledge a number of limitations. The study only assessed the protein expression of three TJs, claudin-1, occludin and ZO-1 following HRV-1B infection. As evident from the $\mathrm{RT}^{2}$ Profiler qPCR data and network analysis, other genes such as PTEN, which are also involved in epithelial barrier integrity, 
were similarly affected following infection. Thus, future investigations utilizing the high-throughput methodology of In-Cell ${ }^{\mathrm{TM}}$ Western could assess the expression of additional junctional proteins. Also, this study utilized a modified human airway epithelial cell culture, thus, will need to be corroborated in primary human AEC to determine the association of HRV infection on modulating TJ gene, protein expression and barrier functionality. Additionally, the potential influence of atopy in tight junction expression and function post infection could not be investigated due to the utilization of airway epithelial cells where this information is not routinely collected and provided. Future studies involving primary human AEC stratified according to atopy could address this. Also, this study only assessed the effects of HRV-1B on TJ disassembly. As demonstrated by Nakagome and colleagues (50), other serotypes of HRV would induce different epithelial responses following infection. Hence, the effects of other HRV serotypes on TJ responses could also be addressed in future studies.

In summary, this study is the first to demonstrate the direct associations between alterations in a number of TJ protein expression and the impaired functionality of the epithelium in regulating passage of macromolecules of varying size following HRV infection. In addition, our study also demonstrates the down-regulation of a range of epithelial junctional genes, CLDN-1, OCLN and in particular, ZO-1 The down-regulation of these epithelial junctional genes following HRV-1B infection was concomitant with a loss in junctional proteins and a subsequent increase in epithelial permeability. Thus, demonstrating the relationship between airway epithelial gene expression, protein and functionality. Furthermore, through network analysis, we are able to identify potential regulatory pathways between anti-viral response and TJ gene expression following HRV-1B infection. When interpreted collectively, our findings strongly suggest the capacity of HRV to effectively disrupt epithelial integrity and attenuating barrier function.

\section{FUNDING}


This work was supported by the National Health and Medical Research Council of Australia (1026494). Stephen M. Stick is a NHMRC Practitioner Fellow.

\section{DECLARATIONS OF INTERESTS}

The authors report no conflicts of interest. The authors alone are responsible for the content and writing of the paper.

\section{ACKNOWLEDGMENTS}

The authors thank Mr Ference van den Bos for his technical assistance and Professor Peter Wark for providing the stocks of HRV-1B utilized in this investigation.

\section{AUTHORS' CONTRIBUTIONS}

Conceived and designed the experiments: AK, GRZ, ANL, KL, SMS and DAK. Performed the experiments: KL. Analyzed the data: KL, AK, DAK and SMS. Technical assistance and analysis: NMT, AB and AGB. Drafted the manuscript: KL. Helped critically revised the manuscript: LWG, TI, KML, KMM EKS, NCS, ENS, GRZ, PJR, ANL, DAK, AK and SMS. All authors have read and approved the manuscript. 


\section{REFERENCES}

1. Roche WR, Montefort S, Baker J, Holgate ST. Cell adhesion molecules and the bronchial epithelium. American Review of Respiratory Diseases. 1993;148(6):S79-82.

2. Sajjan U. Rhinovirus disrupts the barrier function of polarized airway epithelial cells. American Journal of Respiratory and Critical Care Medicine. 2008;178(12):1271.

3. Wark PAB, Bucchieri F, Johnston SL, Gibson PG, Hamilton L, Mimica J, et al. IFN- $\gamma-$ induced protein 10 is a novel biomarker of rhinovirus-induced asthma exacerbations. Journal of Allergy and Clinical Immunology. 2007;120(3):586-93.

4. Xiao C, Puddicombe SM, Field S, Haywood J, Broughton-Head V, Puxeddu I, et al. Defective epithelial barrier function in asthma. Journal of Allergy and Clinical Immunology. 2011;128(3):54956.e12.

5. Rezaee F, Meednu N, Emo JA, Saatian B, Chapman TJ, Naydenov NG, et al. Polyinosinic:polycytidylic acid induces protein kinase D-dependent disassembly of apical junctions and barrier dysfunction in airway epithelial cells. Journal of Allergy and Clinical Immunology. 2011;128(6):1216-24.e11.

6. Umeda K, Ikenouchi J, Katahira-Tayama S, Furuse K, Sasaki H, Nakayama M, et al. ZO-1 and ZO-2 Independently Determine Where Claudins Are Polymerized in Tight-Junction Strand Formation. Cell. 2006;126(4):741-54.

7. Rodgers LS, Beam MT, Anderson JM, Fanning AS. Epithelial barrier assembly requires coordinated activity of multiple domains of the tight junction protein ZO-1. Journal of Cell Science. 2013;126(7):1565-75.

8. Coyne CB, Gambling TM, Boucher RC, Carson JL, Johnson LG. Role of claudin interactions in airway tight junctional permeability. American Journal of Physiology - Lung Cellular and Molecular Physiology. 2003;285(5):L1166-78.

9. McCarthy KM, Skare IB, Stankewich MC, Furuse M, Tsukita S, Rogers RA, et al. Occludin is a functional component of the tight junction. Journal of Cell Science. 1996;109:2287 - 98.

10. Van Itallie CM. ZO-1 stabilizes the tight junction solute barrier through coupling to the perijunctional cytoskeleton. Molecular Biology of the Cell. 2009;20(17):3930.

11. Lopez-Souza N, Dolganov G, Dubin R, Sachs LA, Sassina L, Sporer H, et al. Resistance of differentiated human airway epithelium to infection by rhinovirus. American Journal of Physiology Lung Cellular and Molecular Physiology. 2004;286(2):L373-81.

12. Jakiela B, Brockman-Schneider R, Amineva S, Lee W-M, Gern J. Basal cells of differentiated bronchial epithelium are more susceptible to rhinovirus infection. American Journal of Respiratory Cell and Molecular Biology. 2008;38(5):517-23.

13. Lane C. Epithelial inducible nitric oxide synthase activity is the major determinant of nitric oxide concentration in exhaled breath. Thorax. 2004;59(9):757.

14. Kicic A. Decreased Fibronectin Production Significantly Contributes to Dysregulated Repair of Asthmatic Epithelium. American Journal of Respiratory and Critical Care Medicine. 2010;181(9):889.

15. Kicic A, Sutanto EN, Stevens PT, Knight DA, Stick SM. Intrinsic Biochemical and Functional Differences in Bronchial Epithelial Cells of Children with Asthma. American Journal of Respiratory and Critical Care Medicine. 2006;174(10):1110-8.

16. Lane C. The use of non-bronchoscopic brushings to study the paediatric airway. Respiratory Research. 2005;6(1):53.

17. Kicic A, Stevens PT, Sutanto EN, Kicic-Starcevich E, Ling KM, Looi K, et al. Impaired airway epithelial cell responses from children with asthma to rhinoviral infection. Clinical and experimental allergy : journal of the British Society for Allergy and Clinical Immunology. 2016; In Press.

18. Cory AH, Owen TC, Barltrop JA, Cory JG. Use of an aqueous soluble tetrazolium/formazan assay for cell growth assays in culture. Cancer communications. 1991;3(7):207-12. 
19. Sutanto EN, Kicic A, Foo CJ, Stevens PT, Mullane D, Knight DA, et al. Innate Inflammatory Responses of Pediatric Cystic Fibrosis Airway Epithelial Cells: Effects of Nonviral and Viral Stimulation. American Journal of Respiratory Cell and Molecular Biology. 2011;44(6):761-7.

20. Stutts MJ, Boucher RC, Bromberg PA, Gatzy JT. Effects of ammonium and nitrate salts on ion transport across the excised canine trachea. Toxicology and Applied Pharmacology. 1981;60(1):91-105.

21. Stevens PT. Intrinsic Differences of the Ariway Epithelium in Childhood Allergic Asthma. Perth: University of Western Australia; 2009.

22. Comstock AT, Ganesan S, Chattoraj A, Faris AN, Margolis BL, Hershenson MB, et al. Rhinovirus-Induced Barrier Dysfunction in Polarized Airway Epithelial Cells Is Mediated by NADPH Oxidase 1. Journal of Virology. 2011;85(13):6795-808.

23. Subauste MC, Jacoby DB, Richards SM, Proud D. Infection of a human respiratory epithelial cell line with rhinovirus. Induction of cytokine release and modulation of susceptibility to infection by cytokine exposure. The Journal of Clinical Investigation. 1995;96(1):549-57.

24. Papadopoulos NG, Bates PJ, Bardin PG, Papi A, Leir SH, Fraenkel DJ, et al. Rhinoviruses Infect the Lower Airways. Journal of Infectious Diseases. 2000;181(6):1875-84.

25. Cakebread JA, Haitchi HM, Xu Y, Holgate ST, Roberts G, Davies DE. Rhinovirus-16 Induced Release of IP-10 and IL-8 Is Augmented by Th2 Cytokines in a Pediatric Bronchial Epithelial Cell Model. PLoS One. 2014;9(4):e94010.

26. Tsukita S, Furuse M, Itoh M. Multifunctional strands in tight junctions. Nature Reviews Molecular Cell Biology. 2001;2(4):285-93.

27. Iikura M, Hojo M, Koketsu R, Watanabe S, Sato A, Chino H, et al. The Importance of Bacterial and Viral Infections Associated with Adult Asthma Exacerbations in Clinical Practice. PLoS One. 2015.

28. Einarsson O, Geba GP, Zhu Z, Landry M, Elias JA. Interleukin-11: stimulation in vivo and in vitro by respiratory viruses and induction of airways hyperresponsiveness. Journal of Clinical Investigation. 1996;97(4):915.

29. Terajima M, Yamaya M, Sekizawa K, Okinaga S, Suzuki T, Yamada N, et al. Rhinovirus infection of primary cultures of human tracheal epithelium: role of ICAM-1 and IL-1 $\beta$. American Journal of Physiology. 1997;273(4 Pt 1):L749-59.

30. Sanders S, Kim J, Connolly K, Porter J, Siekierski E, Proud D. Nitric oxide inhibits rhinovirus-induced GM-CSF production in bronchial epithelial cells. Am J Respir Cell Mol Biol. 2001;24:317-25.

31. Schroth MK, Grimm E, Frindt P, Galagan DM, Konno S-I, Love R, et al. Rhinovirus replication causes RANTES production in primary bronchial epithelial cells. American Journal of Respiratory Cell and Molecular Biology. 1999;20(6):1220-8.

32. Donninger H, Glashoff R, Haitchi H-M, Syce JA, Ghildyal R, Van Rensburg E, et al. Rhinovirus induction of the CXC chemokine epithelial-neutrophil activating peptide-78 in bronchial epithelium. Journal of Infectious Diseases. 2003;187(11):1809-17.

33. Spurrell JC, Wiehler S, Zaheer RS, Sanders SP, Proud D. Human airway epithelial cells produce IP-10 (CXCL10) in vitro and in vivo upon rhinovirus infection. American Journal of Physiology-Lung Cellular and Molecular Physiology. 2005;289(1):L85-L95.

34. Kumar R, Herbert C, Yang M, Koskinen A, McKenzie A, Foster P. Role of interleukin - 13 in eosinophil accumulation and airway remodelling in a mouse model of chronic asthma. Clinical \& Experimental Allergy. 2002;32(7):1104-11.

35. Johnson JR, Wiley RE, Fattouh R, Swirski FK, Gajewska BU, Coyle AJ, et al. Continuous exposure to house dust mite elicits chronic airway inflammation and structural remodeling. American Journal of Respiratory and Critical Care Medicine. 2004;169(3):378-85.

36. Grainge CL, Lau LC, Ward JA, Dulay V, Lahiff G, Wilson S, et al. Effect of bronchoconstriction on airway remodeling in asthma. New England Journal of Medicine. 2011;364(21):2006-15. 
37. Yeo N-K, Jang YJ. Rhinovirus infection-induced alteration of tight junction and adherens junction components in human nasal epithelial cells. The Laryngoscope. 2010;120(2):346-52.

38. Wark PAB, Johnston SL, Bucchieri F, Powell R, Puddicombe S, Laza-Stanca V, et al. Asthmatic bronchial epithelial cells have a deficient innate immune response to infection with rhinovirus. Journal of Experimental Medicine. 2005;201(6):937-47.

39. Zheng S, De Bishnu P, Choudhary S, Comhair SA, Goggans T, Slee R, et al. Impaired innate host defense causes susceptibility to respiratory virus infections in cystic fibrosis. Immunity. 2003;18(5):619-30.

40. Kicic A, Stevens PT, Sutanto EN, Kicic-Starcevich E, Ling K-M, Looi K, et al. Impaired airway epithelial cell responses from children with asthma to rhinoviral infection. Clinical \& Experimental Allergy. 2016:n/a-n/a.

41. Kawai T, Akira S. Innate immune recognition of viral infection. Nature immunology. 2006;7(2):131-7.

42. Sato M, Suemori H, Hata N, Asagiri M, Ogasawara K, Nakao K, et al. Distinct and Essential Roles of Transcription Factors IRF-3 and IRF-7 in Response to Viruses for IFN- $\alpha / \beta$ Gene Induction. Immunity. 2000;13(4):539-48.

43. Yoneyama M, Suhara W, Fukuhara Y, Fukuda M, Nishida E, Fujita T. Direct triggering of the type I interferon system by virus infection: activation of a transcription factor complex containing IRF - 3 and CBP/p300. The EMBO Journal. 1998;17(4):1087-95.

44. Lin R, Heylbroeck C, Pitha PM, Hiscott J. Virus-Dependent Phosphorylation of the IRF-3 Transcription Factor Regulates Nuclear Translocation, Transactivation Potential, and ProteasomeMediated Degradation. Molecular and Cellular Biology. 1998;18(5):2986-96.

45. Bosco A, Wiehler S, Proud D. Interferon regulatory factor 7 regulates airway epithelial cell responses to human rhinovirus infection. BMC genomics. 2016;17(1):1.

46. Dinkova-Kostova AT, Talalay P. NAD (P) H: quinone acceptor oxidoreductase 1 (NQO1), a multifunctional antioxidant enzyme and exceptionally versatile cytoprotector. Archives of Biochemistry and Biophysics. 2010;501(1):116-23.

47. Matsumoto Y, Van Thuy TT, Hai H, Suoh M, Urahara Y, Motoyama H, et al. Cytoglobin deficiency promotes liver cancer development from hepatosteatosis through activation of the oxidative stress pathway. The American journal of pathology. 2015;185(4):1045-60.

48. Hashimoto M, Hsu LJ, Rockenstein E, Takenouchi T, Mallory M, Masliah E. $\alpha$-Synuclein protects against oxidative stress via inactivation of the c-Jun $\mathrm{N}$-terminal kinase stress-signaling pathway in neuronal cells. Journal of Biological Chemistry. 2002;277(13):11465-72.

49. Ding Y, Winters A, Ding M, Graham S, Akopova I, Muallem S, et al. Reactive oxygen species-mediated TRPC6 protein activation in vascular myocytes, a mechanism for vasoconstrictorregulated vascular tone. Journal of Biological Chemistry. 2011;286(36):31799-809.

50. Nakagome K, Bochkov YA, Ashraf S, Brockman-Schneider RA, Evans MD, Pasic TR, et al. Effects of rhinovirus species on viral replication and cytokine production. Journal of Allergy and Clinical Immunology. 2014;134(2):332-41. e10. 
Figure 1 Reduction in cell viability, increased apoptotic response and viral replication in NuLi1 after viral infection: (A) After infection with a range of HRV-1B titres $\left(2.5-80 \times 10^{4} \mathrm{TCID}_{50} / \mathrm{ml}\right)$, cell viability was assessed at 24, 48 and $72 \mathrm{~h}$ post infection via a 3-[4,5-dimethylthiazol-2yl]-5-[3carboxymethoxyphenyl]-2-[4-sulfophenyl] 2H-tetrazolium inner salt (MTS) assay. Results presented as whisker box plots (median, Min - Max) in percentages from at least three different experiments with each data assayed in triplicate and normalized to non-infected control cells (---). Infection with HRV-1B caused a time and dose-dependent cytotoxic effect on NuLi-1 cells. (B) After infection with a range of HRV-1B titres $\left(2.5-40 \times 10^{4} \mathrm{TCID} 50 / \mathrm{ml}\right)$ for $24 \mathrm{~h}$, apoptotic response of the cells was determined using a colorimetric assay ssDNA apoptosis kit; and it was observed overall apoptotic response increased significantly at all viral titres $(p<0.05)$. Data presented as whisker box plots (median, Min - Max) in percentages from at least three different experiments with each data assayed in triplicate relative to non-infected control cells. (C) NuLi-1 cells were established and infected with a range of $\mathrm{HRV}-1 \mathrm{~B}$ titres $\left(2.5-40 \times 10^{4} \mathrm{TCID} 50 / \mathrm{ml}\right)$ for $24 \mathrm{~h}$. Cells were harvested to extract RNA and HRV-1B RNA measured using qPCR. Viral copy number increased with increasing viral titre and was significant for all viral titres used $(p<0.05)$. Data were normalized to microgram RNA and presented as whisker box plots (median, Min - Max) from at least three different experiments with each data assayed in triplicates. Kruskal-Wallis with Dunn's multiple comparison post-hoc tested for statistical significance. $*$ denotes significance relative to control $(p<0.05)$.

Figure 2 Effect of HRV-1B infection on membrane TJ protein expression and transepithelial permeability in NuLi-1 and primary airway epithelial cells (AEC): (A - B) Representative images of In-Cell ${ }^{\mathrm{TM}}$ Western assay of NuLi-1 $(\mathrm{n}=5)$ and primary AECs $(\mathrm{n}=3)$ following $24 \mathrm{~h} \mathrm{HRV-1B}$ infection illustrating signal intensity of TJ proteins and cell and nuclear stains. (TJ: TJ protein stain [OCLN: occludin; CLDN1: claudin-1; ZO-1: zonula occluden-1]; CN: Cell and nuclear stain; M: Merged) (C) After infection with HRV-1B titres (2.5 and 20x10 $\left.\mathrm{TCID}_{50} / \mathrm{ml}\right)$ for $24 \mathrm{~h}$, membrane TJ protein expression as assessed via In-Cell ${ }^{\mathrm{TM}}$ Western assay was quantified. As observed, overall 
membrane claudin-1, occludin and ZO-1 protein expression decreased following exposure to HRV$1 \mathrm{~B}$ at both viral titres. (D) Significant decrease in all $3 \mathrm{TJ}$ membrane protein was similarly observed in primary AECs following HRV-1B infection with a viral titre of $10 \times 10^{4} \mathrm{TCID}_{50} / \mathrm{ml}$ for $24 \mathrm{~h}$. Kruskal-Wallis with Dunn's multiple comparison post-hoc analysis tested for statistical significance for all three TJ proteins $(p<0.05)$. Data were normalized to cell numbers and whisker box plots (median, Min - Max); $n=5$ for NuLi-1; $\mathrm{n}=3$ for primary AECs individual experiments each performed in triplicates. (E) After infection with HRV-1B titres $\left(2.5\right.$ and $\left.20 \times 10^{4} \mathrm{TCID}_{50} / \mathrm{ml}\right)$ for 24 h, epithelial permeability was assessed via a transepithelial permeability assay. As observed, overall transepithelial permeability to FITC-dextran $4 \mathrm{kDa}$ and $20 \mathrm{kDa}$ was significantly increased at both viral titres $(p<0.05)$. Results are presented as whisker box plots (median, Min - Max); $n=5$ individual experiments each performed in triplicates. (F) After infection with HRV-1B titre of 10x10 $\mathrm{TCID}_{50} / \mathrm{ml}$ for $24 \mathrm{~h}$, significant increase in transepithelial permeability was only observed for FITCdextran $4 \mathrm{kDa}$ in primary AECs $(p<0.05)$. Results are presented as whisker box plots (median, Min - Max); $n=3$ individual experiments each performed in triplicates. Kruskal-Wallis with Dunn's multiple comparison post-hoc tested for statistical significance. * denotes significance relative to noninfected control $(p<0.05)$. " denotes significance relative to $20 \mathrm{kDa}(p<0.05)$.

Figure 3: Interaction network of human tight junction and anti-viral response in airway epithelial cells obtained by Ingenuity ${ }^{\circledR}$ Pathway Analysis (IPA $\left.{ }^{\circledR}\right)$. Molecular interaction between genes was illustrated through the construction of network interaction diagrams utilizing the Ingenuity Systems Knowledge Base. (A) Interactions between the 3 tight junctions of interest in airway epithelial cells identified TJPI (ZOI) being the most interactive gene followed by occludin (OCLN) and claudin-1 (CLDN1), exhibiting 26, 12 and 9 functional interactions with other TJ respectively. (B) Network interactions between genes encoding for human tight junction and anti-viral responses in airway epithelial cells obtained by IPA ${ }^{\circledR}$ illustrated multiple complex interactions and identifying IL15 as a hub gene with interactions to 7 genes within the TJ network. A potential regulatory pathway 
for TJ expression through IL15 and IRF3 was also identified from the network interaction analysis. Up- and down-regulated genes in red and green, respectively.

Table 1: Demographic data for participants recruited to the study

Table 2: Human tight junction genes that were up- or down-regulated in modified human airway epithelial cells following HRV-1B infection as determined by $\mathrm{RT}^{2}$ profiler focused qPCR array.

Table 3: Human anti-viral response genes that were up- or down-regulated in modified human airway epithelial cells following HRV-1B infection as determined by $\mathrm{RT}^{2}$ profiler focused qPCR array. 
Table 1 Demographic data for participants recruited to the study

\begin{tabular}{lcccccc}
\hline & Number & Gender (M/F) & Mean Age (Range) & $\begin{array}{c}\text { Mean IgE } \\
\text { (IU/L) }\end{array}$ & Allergies & Hay Fever / Eczema / Both \\
\hline Non-asthmatic & 3 & $2 / 1$ & $4.6(3.4-6.4)$ & 17 & 0 & 0 \\
\hline
\end{tabular}

M -male; F - Female 
Table 2: Human tight junction genes that were up- or down-regulated in modified human airway epithelial cells following HRV-1B infection as determined by RT $^{2}$ profiler focused qPCR array.

\begin{tabular}{|c|c|c|c|}
\hline Gene Symbol & Gene Description & Fold Up/Down & P Value \\
\hline CLDN8 & Claudin 8 & -14.30 & 0.05077 \\
\hline PECAM1 & Platelet/endothelial cell adhesion molecule & -4.31 & 0.07098 \\
\hline SPTA1 & Spectrin, alpha, erythrocytic 1 (elliptocytosis 2) & -3.65 & 0.08105 \\
\hline PTEN & Phosphatase and tensin homolog & -3.51 & 0.04063 \\
\hline CLDN19 & Claudin 19 & -3.46 & 0.10757 \\
\hline MAGI2 & Membrane associated guanylate kinase, WW and PDZ domain containing 2 & -3.27 & 0.29596 \\
\hline IGSF5 & Immunoglobulin superfamily, member 5 & -3.21 & 0.2049 \\
\hline ESAM & Endothelial cell adhesion molecule & -2.73 & 0.39208 \\
\hline CLDN12 & Claudin 12 & -2.31 & 0.03772 \\
\hline ICAM2 & Intercellular adhesion molecule 2 & -2.11 & 0.34791 \\
\hline ARHGEF2 & Rho/rac guanine nucleotide exchange factor (GEF) 2 & -2.06 & 0.13813 \\
\hline ASH1L & Ash1 (absent, small, or homeotic)-like (Drosophila) & -1.95 & 0.03865 \\
\hline ZAK & Sterile alpha motif and leucine zipper containing kinase AZK & -1.93 & 0.08563 \\
\hline CLDN14 & Claudin 14 & -1.90 & 0.27774 \\
\hline CLDN3 & Claudin 3 & -1.89 & 0.16849 \\
\hline SPTB & Spectrin, beta, erythrocytic & -1.84 & 0.07891 \\
\hline MLLT4 & $\begin{array}{c}\text { Myeloid/lymphoid or mixed-lineage leukemia (trithorax homolog, Drosophila); } \\
\text { translocated to, } 4\end{array}$ & -1.82 & 0.10406 \\
\hline CLDN9 & Claudin 9 & -1.81 & 0.15737 \\
\hline CRB1 & Crumbs homolog 1 (Drosophila) & -1.81 & 0.11888 \\
\hline VAPA & VAMP (vesicle-associated membrane protein)-associated protein $\mathrm{A}, 33 \mathrm{kDa}$ & -1.73 & 0.06933 \\
\hline PARD3 & Par-3 partitioning defective 3 homolog (C. elegans) & -1.70 & 0.1556 \\
\hline TJP3 & Tight junction protein 3 (zona occludens 3 ) & -1.64 & 0.20543 \\
\hline CLDN15 & Claudin 15 & -1.62 & 0.18782 \\
\hline CLDN5 & Claudin 5 & -1.58 & 0.16883 \\
\hline CSNK2A2 & Casein kinase 2 , alpha prime polypeptide & -1.52 & 0.16144 \\
\hline CTNNA3 & Catenin (cadherin-associated protein), alpha 3 & -1.51 & 0.1226 \\
\hline PARD6B & Par- 6 partitioning defective 6 homolog beta (C. elegans) & -1.48 & 0.36591 \\
\hline JAM2 & Junctional adhesion molecule 2 & -1.45 & 0.10841 \\
\hline ACTN2 & Actinin, alpha 2 & -1.39 & 0.18307 \\
\hline
\end{tabular}




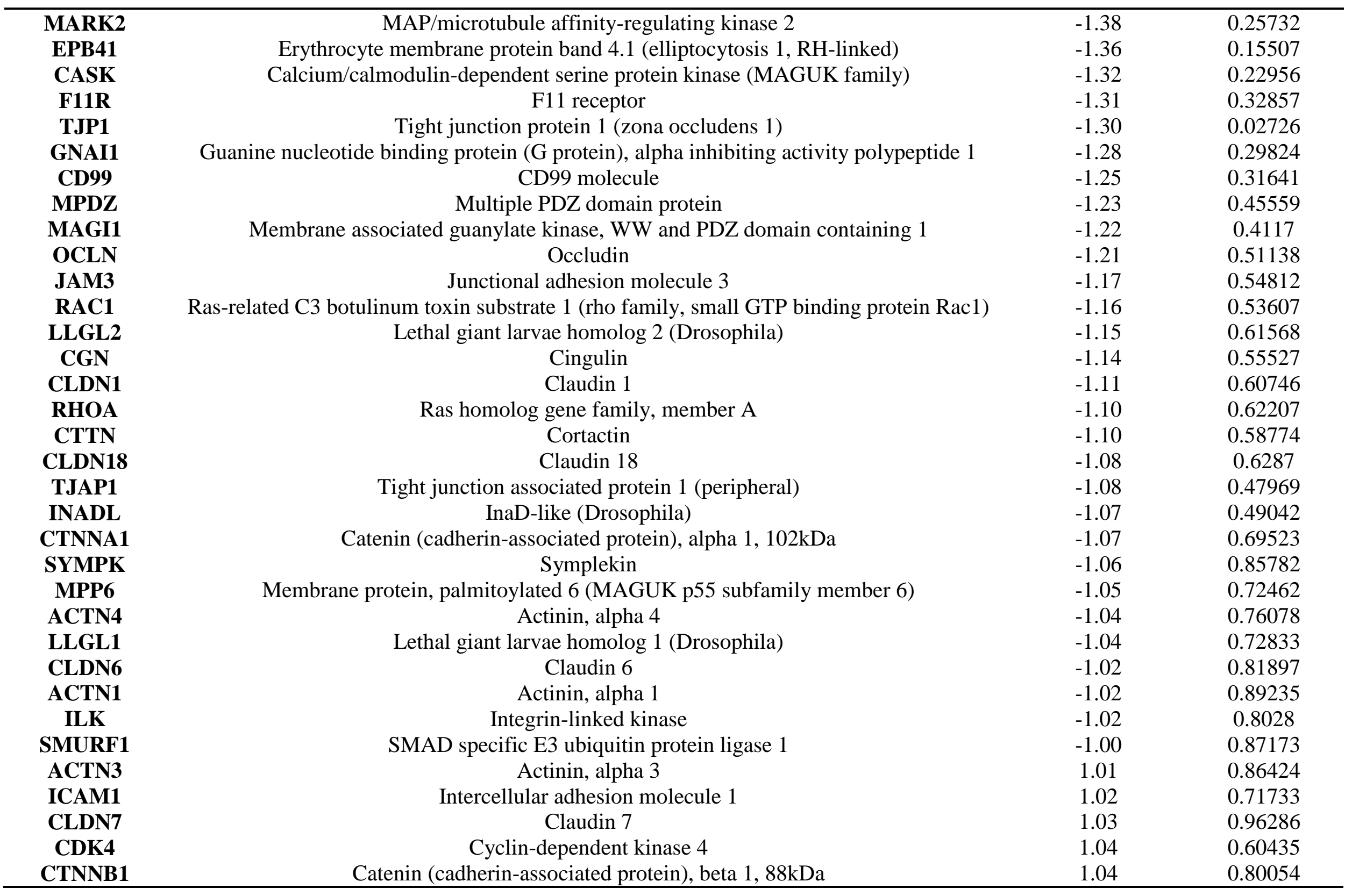




\begin{tabular}{ccc}
\hline AMOTL1 & Angiomotin like 1 & 1.04 \\
CLDN10 & Claudin 10 & 1.06 \\
CTNNA2 & Catenin (cadherin-associated protein), alpha 2 & 1.07 \\
TJP2 & Tight junction protein 2 (zona occludens 2) & 1.19 \\
CLDN11 & Claudin 11 & 0.91476 \\
PRKCI & Protein kinase C, iota & 0.90389 \\
CSDA & Cold shock domain protein A & 0.57443 \\
MPP5 & Membrane protein, palmitoylated 5 (MAGUK p55 subfamily member 5) & 0.25665 \\
HCLS1 & Hematopoietic cell-specific Lyn substrate 1 & 0.44612 \\
CLDN17 & Claudin 17 & 0.43812 \\
SPTAN1 & Spectrin, alpha, non-erythrocytic 1 (alpha-fodrin) & 0.4365 \\
CSNK2A1 & Casein kinase 2, alpha 1 polypeptide & 0.20818 \\
CLDN2 & Claudin 2 & 0.73856 \\
PRKCZ & Protein kinase C, zeta & 0.39112 \\
TIAM1 & T-cell lymphoma invasion and metastasis 1 & 0.35 \\
CDC42 & Cell division cycle 42 (GTP binding protein, 25kDa) & 1.33 \\
CLDN16 & Claudin 16 & 1.33 \\
CLDN4 & Claudin 4 & 1.35 \\
CSNK2B & Carein kinase 2, beta polypeptide & 1.39 \\
PARD6A & Crumbs homolog 3 (Drosophila) & 1.41 \\
CRB3 & & 0.22708 \\
\end{tabular}


Table 3: Human anti-viral response genes that were up- or down-regulated in modified human airway epithelial cells following HRV-1B infection as determined by $\mathbf{R T}^{2}$ profiler focused qPCR array.

\begin{tabular}{|c|c|c|c|}
\hline Gene Symbol & Gene Description & Fold Up/Down & P Value \\
\hline CXCL9 & Chemokine (C-X-C motif) ligand 9 & -2.93 & 0.00000047 \\
\hline CARD9 & Caspase recruitment domain family, member 9 & -2.86 & 0.00004748 \\
\hline IRAK1 & Interleukin-1 receptor-associated kinase 1 & -2.75 & 0.00001615 \\
\hline DAK & Dihydroxyacetone kinase 2 homolog (S. cerevisiae) & -2.29 & 0.00020652 \\
\hline NOD2 & Nucleotide-binding oligomerization domain containing 2 & -2.18 & 0.00000001 \\
\hline SPP1 & Secreted phosphoprotein 1 & -2.17 & 0.00001152 \\
\hline TLR7 & Toll-like receptor 7 & -2.05 & 0.00051151 \\
\hline PIN1 & Peptidylprolyl cis/trans isomerase, NIMA-interacting 1 & -1.97 & 0.00000001 \\
\hline IRF7 & Interferon regulatory factor 7 & -1.83 & 0.00002603 \\
\hline TRADD & TNFRSF1A-associated via death domain & -1.67 & 0.00909072 \\
\hline MAVS & Mitochondrial antiviral signaling protein & -1.67 & 0.00000035 \\
\hline PSTPIP1 & Proline-serine-threonine phosphatase interacting protein 1 & -1.52 & 0.00008138 \\
\hline CASP10 & Caspase 10, apoptosis-related cysteine peptidase & -1.52 & 0.00006931 \\
\hline FADD & Fas (TNFRSF6)-associated via death domain & -1.43 & 0.00000001 \\
\hline MAPK14 & Mitogen-activated protein kinase 14 & -1.43 & 0.03774484 \\
\hline MAPK3 & Mitogen-activated protein kinase 3 & -1.43 & 0.01045563 \\
\hline JUN & Jun proto-oncogene & -1.41 & 0.00029771 \\
\hline CTSB & Cathepsin B & -1.34 & 0.00071302 \\
\hline MAP2K1 & Mitogen-activated protein kinase kinase 1 & -1.33 & 0.00072620 \\
\hline IRF5 & Interferon regulatory factor 5 & -1.32 & 0.33829921 \\
\hline CD40 & CD40 molecule, TNF receptor superfamily member 5 & -1.30 & 0.00051747 \\
\hline RELA & V-rel reticuloendotheliosis viral oncogene homolog A (avian) & -1.20 & 0.00000423 \\
\hline MAPK1 & Mitogen-activated protein kinase 1 & -1.19 & 0.30268804 \\
\hline IFNA1 & Interferon, alpha 1 & -1.18 & 0.00023519 \\
\hline FOS & FBJ murine osteosarcoma viral oncogene homolog & -1.17 & 0.03137685 \\
\hline MAP3K1 & Mitogen-activated protein kinase kinase kinase 1 & -1.17 & 0.13164653 \\
\hline RIPK1 & Receptor (TNFRSF)-interacting serine-threonine kinase 1 & -1.10 & 0.02094787 \\
\hline CHUK & Conserved helix-loop-helix ubiquitous kinase & -1.09 & 0.03574090 \\
\hline TRAF6 & TNF receptor-associated factor 6 & -1.09 & 0.17437058 \\
\hline NLRP3 & NLR family, pyrin domain containing 3 & -1.08 & 0.00040454 \\
\hline
\end{tabular}




\begin{tabular}{|c|c|c|c|}
\hline NFKB1 & Nuclear factor of kappa light polypeptide gene enhancer in B-cells 1 & -1.08 & 0.00507649 \\
\hline OAS2 & 2'-5'-oligoadenylate synthetase $2,69 / 71 \mathrm{kDa}$ & -1.07 & 0.00784655 \\
\hline NFKBIA & Nuclear factor of kappa light polypeptide gene enhancer in B-cells inhibitor, alpha & -1.07 & 0.00004979 \\
\hline МАРК8 & Mitogen-activated protein kinase 8 & -1.06 & 0.09300370 \\
\hline ATG5 & ATG5 autophagy related 5 homolog (S. cerevisiae) & -1.02 & 0.89788235 \\
\hline DDX3X & DEAD (Asp-Glu-Ala-Asp) box polypeptide 3, X-linked & -1.02 & 0.72534872 \\
\hline TLR3 & Toll-like receptor 3 & -1.02 & 0.87838850 \\
\hline IL1B & Interleukin 1 , beta & -1.01 & 0.78185343 \\
\hline IKBKB & Inhibitor of kappa light polypeptide gene enhancer in B-cells, kinase beta & -1.01 & 0.79643923 \\
\hline TRAF3 & TNF receptor-associated factor 3 & 1.01 & 0.96555616 \\
\hline HSP90AA1 & Heat shock protein 90kDa alpha (cytosolic), class A member 1 & 1.07 & 0.03711316 \\
\hline IFNAR1 & Interferon (alpha, beta and omega) receptor 1 & 1.07 & 0.03577578 \\
\hline AZI2 & 5 -azacytidine induced 2 & 1.08 & 0.51377372 \\
\hline CASP8 & Caspase 8 , apoptosis-related cysteine peptidase & 1.11 & 0.80836990 \\
\hline ISG15 & ISG15 ubiquitin-like modifier & 1.12 & 0.00554821 \\
\hline MAP2K3 & Mitogen-activated protein kinase kinase 3 & 1.13 & 0.12194074 \\
\hline CYLD & Cylindromatosis (turban tumor syndrome) & 1.14 & 0.01209585 \\
\hline STAT1 & Signal transducer and activator of transcription $1,91 \mathrm{kDa}$ & 1.16 & 0.24645673 \\
\hline MYD88 & Myeloid differentiation primary response gene (88) & 1.18 & 0.00002183 \\
\hline TICAM1 & Toll-like receptor adaptor molecule 1 & 1.18 & 0.00492646 \\
\hline CCL3 & Chemokine (C-C motif) ligand 3 & 1.18 & 0.00000032 \\
\hline PYDC1 & PYD (pyrin domain) containing 1 & 1.18 & 0.00000032 \\
\hline AIM2 & Absent in melanoma 2 & 1.19 & 0.44973387 \\
\hline IL18 & Interleukin 18 (interferon-gamma-inducing factor) & 1.21 & 0.00049428 \\
\hline CD80 & CD80 molecule & 1.24 & 0.00105612 \\
\hline IRF3 & Interferon regulatory factor 3 & 1.24 & 0.00991388 \\
\hline PYCARD & PYD and CARD domain containing & 1.25 & 0.00141023 \\
\hline CTSL1 & Cathepsin L1 & 1.27 & 0.35211584 \\
\hline TRIM25 & Tripartite motif containing 25 & 1.28 & 0.10898547 \\
\hline CASP1 & Caspase 1, apoptosis-related cysteine peptidase (interleukin 1, beta, convertase) & 1.29 & 0.00143938 \\
\hline MX1 & Myxovirus (influenza virus) resistance 1 , interferon-inducible protein p78 (mouse) & 1.30 & 0.00000021 \\
\hline IFIH1 & Interferon induced with helicase $\mathrm{C}$ domain 1 & 1.30 & 0.00012226 \\
\hline IFNB1 & Interferon, beta 1 , fibroblast & 1.31 & 0.00129833 \\
\hline DHX58 & DEXH (Asp-Glu-X-His) box polypeptide 58 & 1.33 & 0.23093048 \\
\hline
\end{tabular}




\begin{tabular}{|c|c|c|c|}
\hline IL15 & Interleukin 15 & 1.36 & 0.00006954 \\
\hline SUGT1 & SGT1, suppressor of G2 allele of SKP1 (S. cerevisiae) & 1.49 & 0.00505288 \\
\hline CD86 & CD86 molecule & 1.50 & 0.00493762 \\
\hline MAP3K7 & Mitogen-activated protein kinase kinase kinase 7 & 1.51 & 0.00459035 \\
\hline CTSS & Cathepsin S & 1.56 & 0.00000325 \\
\hline MEFV & Mediterranean fever & 1.57 & 0.00000002 \\
\hline TNF & Tumor necrosis factor & 1.59 & 0.01890268 \\
\hline APOBEC3G & Apolipoprotein B mRNA editing enzyme, catalytic polypeptide-like $3 \mathrm{G}$ & 1.71 & 0.04202078 \\
\hline CXCL11 & Chemokine (C-X-C motif) ligand 11 & 1.75 & 0.00000834 \\
\hline CXCL10 & Chemokine (C-X-C motif) ligand 10 & 1.80 & 0.00007272 \\
\hline TBK1 & TANK-binding kinase 1 & 1.82 & 0.00000658 \\
\hline CCL5 & Chemokine (C-C motif) ligand 5 & 1.85 & 0.00006885 \\
\hline IL8 & Interleukin 8 & 2.05 & 0.00003576 \\
\hline IL12A & $\begin{array}{l}\text { Interleukin } 12 \mathrm{~A} \text { (natural killer cell stimulatory factor } 1 \text {, cytotoxic lymphocyte maturation factor } 1 \text {, } \\
\text { p35) }\end{array}$ & 2.08 & 0.00000066 \\
\hline DDX58 & DEAD (Asp-Glu-Ala-Asp) box polypeptide 58 & 2.32 & 0.00370093 \\
\hline IL6 & Interleukin 6 (interferon, beta 2) & 2.56 & 0.00000002 \\
\hline TLR9 & Toll-like receptor 9 & 2.65 & 0.03062186 \\
\hline TLR8 & Toll-like receptor 8 & 3.27 & 0.00000000 \\
\hline IL12B & $\begin{array}{l}\text { Interleukin } 12 \mathrm{~B} \text { (natural killer cell stimulatory factor } 2 \text {, cytotoxic lymphocyte maturation factor } 2 \text {, } \\
\text { p40) }\end{array}$ & 3.29 & 0.00044460 \\
\hline IFNA2 & Interferon, alpha 2 & 6.13 & 0.00000001 \\
\hline
\end{tabular}


A
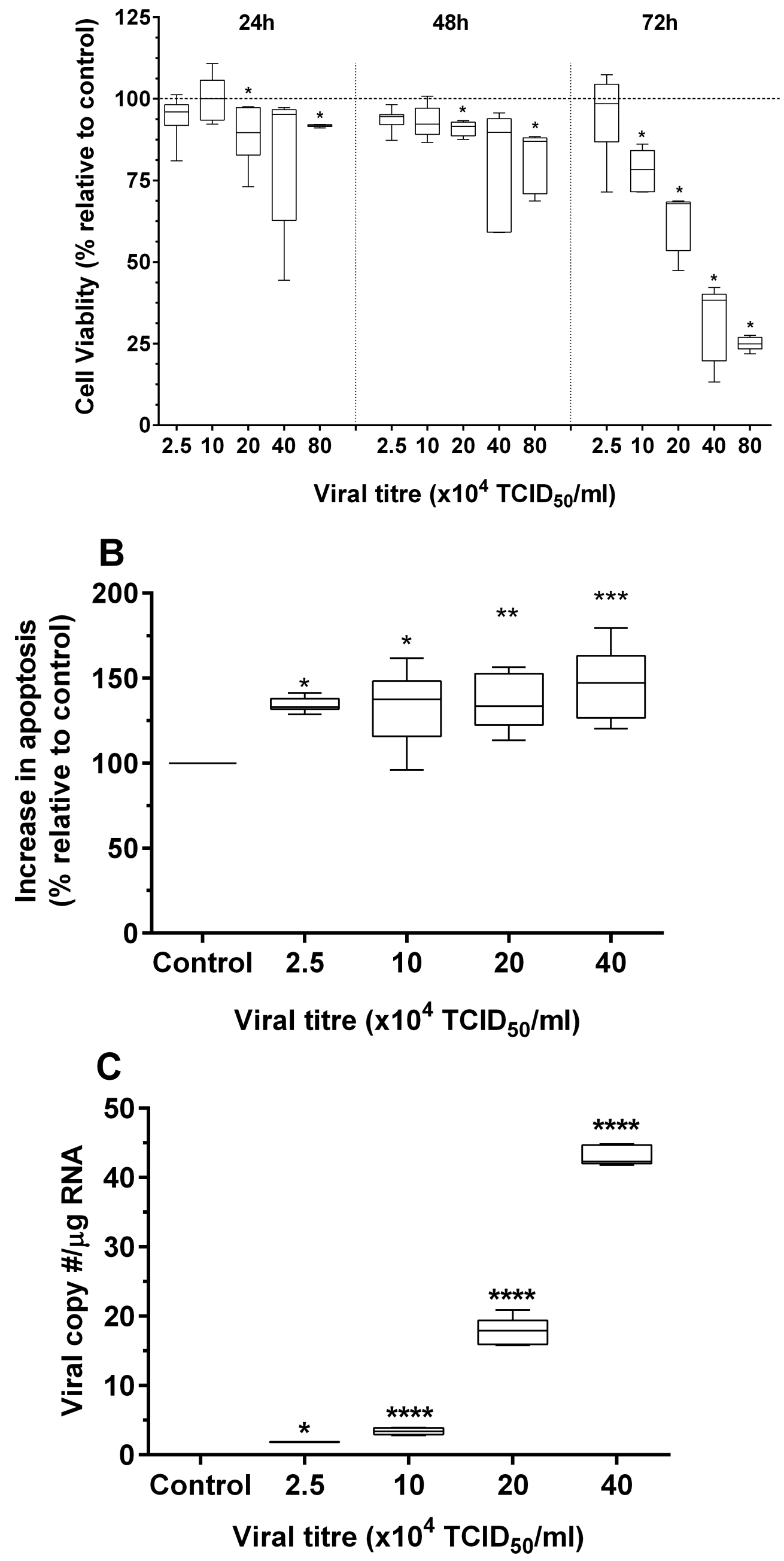
A

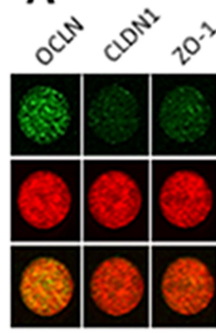

Non-infected

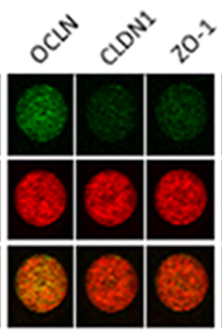

$2.5 \times 10^{4} \mathrm{TCID}_{\mathrm{so}} / \mathrm{ml} 20 \times 10^{4} \mathrm{TCID}_{\mathrm{so}} / \mathrm{ml}$

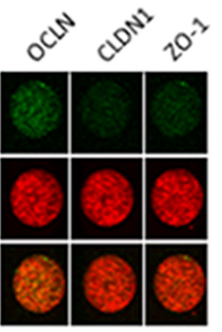

B

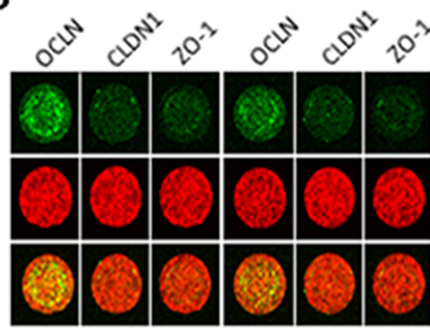

Non-infected $10 \times 10^{4} \mathrm{TCID}_{\mathrm{s}} / \mathrm{ml}$

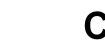

흥

C

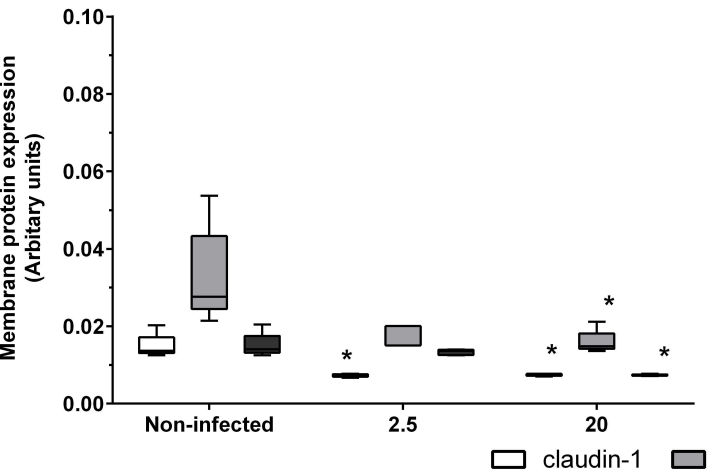

Viral titre $\left(\times 10^{4} \mathrm{TCID}_{50} / \mathrm{ml}\right)$
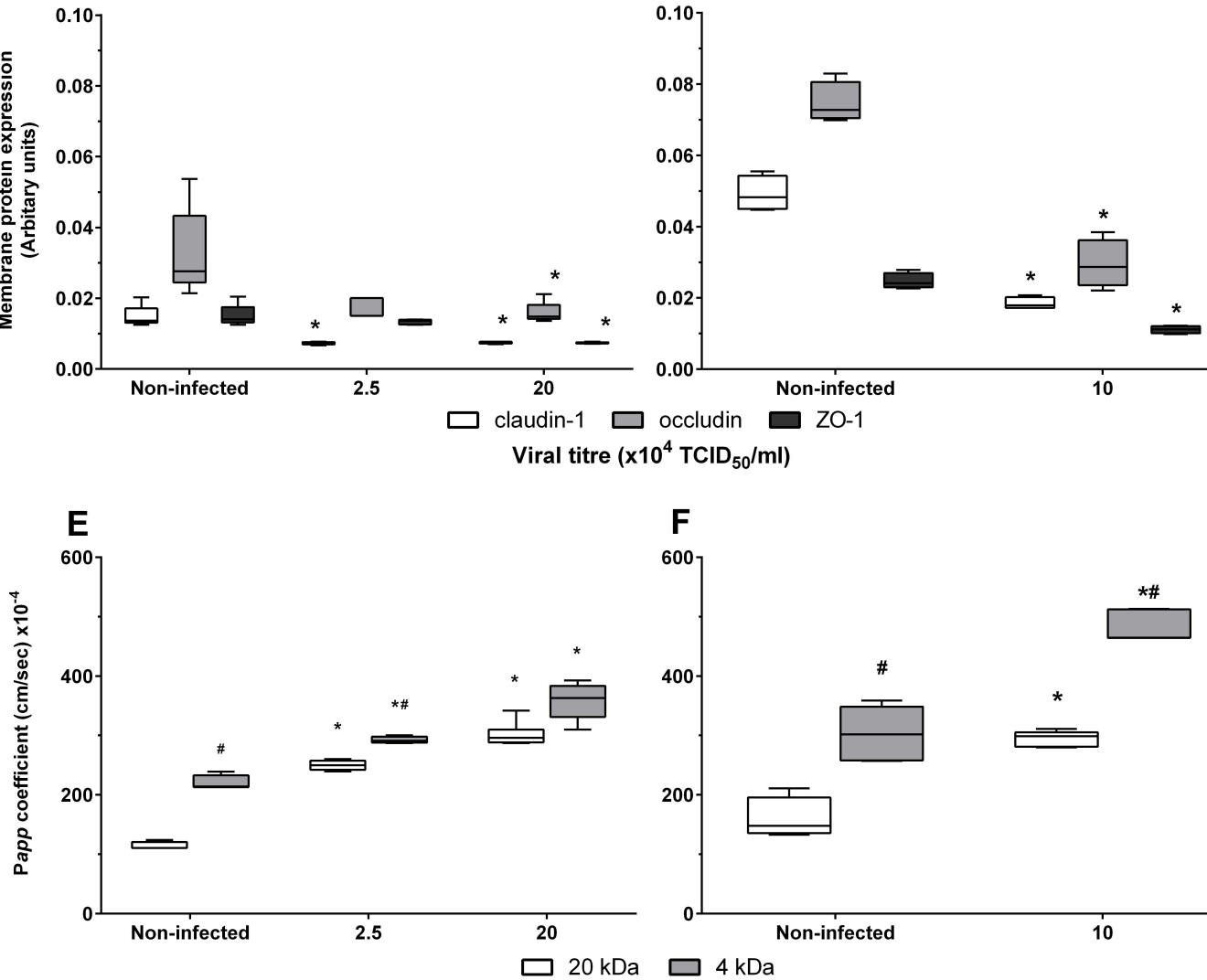

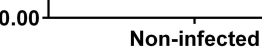

ZO-1

10

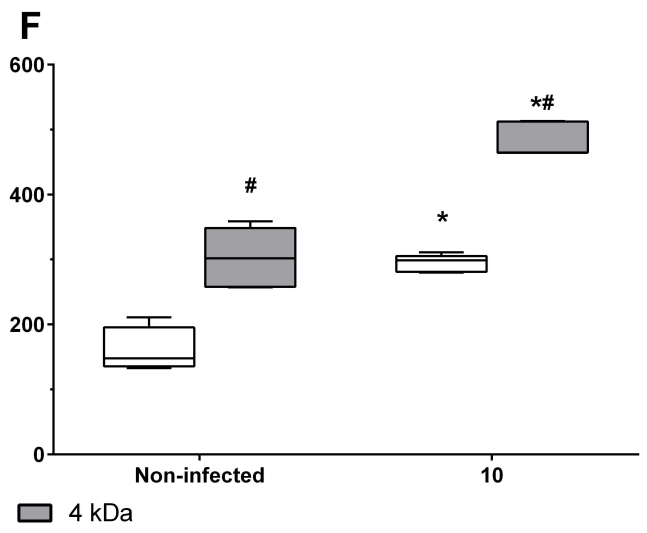

Viral titre $\left(\times 10^{4} \mathrm{TCID}_{50} / \mathrm{ml}\right)$ 
